\title{
Correction to: The ZJU index is a powerful index for identifying NAFLD in the general Chinese population
}

\author{
Linman $\mathrm{Li}^{1}$ (i) $\cdot$ Wenyi You ${ }^{2} \cdot$ Wei Ren ${ }^{3}$
}

Published online: 26 September 2019

(C) Springer-Verlag Italia S.r.l., part of Springer Nature 2019

Correction to: Acta Diabetol (2017) 54:905-911

https://doi.org/10.1007/s00592-017-1024-8

In paragraph Index calculation formulae, Point 2 should read as follows:

$\mathrm{VAI}=[\mathrm{WC} /(39.68+(1.88 \times \mathrm{BMI}))] \times(\mathrm{TG} / 1.03) \times(1.31 /$ $\mathrm{HDL})$ for males; $[\mathrm{WC} /(36.58+(1.89 \times \mathrm{BMI}))] \times(\mathrm{TG} / 0.81)$ $\times(1.52 / \mathrm{HDL})$ for females [21].

Publisher's Note Springer Nature remains neutral with regard to jurisdictional claims in published maps and institutional affiliations.

The original article can be found online at https://doi.org/10.1007/ s00592-017-1024-8.

Linman $\mathrm{Li}$

1360896542@qq.com

1 Department of Physical Examination, The First Affiliated Hospital of Chongqing Medical University, Chongqing 400016, People's Republic of China

2 Infectious Diseases Department, The People's Hospital of Yubei, District of Chongqing City, Chongqing 401120, People's Republic of China

3 Department of Endocrinology, The First Affiliated Hospital of Chongqing Medical University, Chongqing 400016, People's Republic of China 